\title{
Viability of Food Waste to Biogas Energy Through Anaerobic Digestion
}

\author{
Shemsedin Ahmed ${ }^{1 *} \quad$ Admasu Adamu ${ }^{1} \quad$ Abiyot Abera $^{2}$ \\ 1.Wolaita Sodo University, College of Natural and Computational Science, Department of Environmental \\ Science, Wolaita Sodo, Ethiopia \\ 2. Wachamo University, College of Natural and Computational Science, Department of Environmental \\ Science,Hosaina, Ethiopia
}

\begin{abstract}
This study was conducted on the feasibility of food waste for biogas production in Wolaita Sodo University, Ethiopia. The study aimed to investigate the potential of different food waste categories for biogas production through anaerobic digestion. A total of 40 representative food waste samples with 100 grams each were collected from four source-separated food waste categories based on the various food menus of the University. The collected food waste samples were tested for $\% \mathrm{TS}, \% \mathrm{TN}, \% \mathrm{TVS}$ and $\% \mathrm{TC}$. Besides, laboratory-scale anaerobic digestions were carried out exhaustively for each food sample for 25 days at $35^{\circ} \mathrm{C}$. Thus, the proportion of $\mathrm{CH}_{4}$ and $\mathrm{CO}_{2}$ of the biogas produced from each food waste categories was also evaluated. The analysis was done using IBM SPSS Statistics 21. Results showed that \%TN, \%TS, \%TVS and \%TC were 1.62\%, 30.75\%, $29.29 \%$ and $16.27 \%$, respectively. Small C: N ratio (10:1) was scored. The ratio of VS: TS was very high (95\%). The mean $\mathrm{CH}_{4}$ proportion produced from ISV, RB, IML and MA were 61, 65, 63 and 63 respectively. However, the mean $\mathrm{CO}_{2}$ proportion produced from ISV, RB, IML and MA were 22, 20.5, 15.5 and 16 respectively. Thus, the proportion of $\mathrm{CH}_{4}$ produced $61-65 \%$ and high ratio of VS: TS showed the viability of all food waste categories to biogas energy production. However, the small $\mathrm{C}: \mathrm{N}$ ratio which is an indicator for the resistance of anaerobic digestion implied in need of other organic wastes rich in carbon content to the reactor. In general, the food wastes generated from WSU students' cafeteria are a promising feedstock for anaerobic digesters concerning biogas production.
\end{abstract}

Keywords: Food waste, Anaerobic digestion, $\mathrm{C}$ : $\mathrm{N}$ ratio, $\% \mathrm{CH}_{4}, \mathrm{CO}_{2}$ and Biogas

DOI: $10.7176 / \mathrm{JETP} / 10-4-01$

Publication date:August $31^{\text {st }} 2020$

\section{Introduction}

Providing sufficient energy for the ever-increasing demand for energy to meet the growing world population with rising living standards required major advances in energy supply and efficiency (Dinçer and Abu-Rayash, 2019). Besides, the use of fossil fuels with a limited amount as sources of energy has resulted in increased air emissions, global warming, and climate change attracting unparalleled attention from scientific and political communities at the national and global levels (Bernstein et al., 2008). Hence the ever-increasing interest in using sustainable renewable energy sources to meet energy demand and rising environmental impacts (Kalmár and Nagy, 2007). Among these, biogas energy mainly based on anaerobic digestion of organic wastes as an alternative renewable source of energy is increasingly gaining attention in developing countries (Abdulkareem, 2005). Anaerobic digestion is a process carried out by microorganism in an oxygen-free environment; with the generation of biogas mainly methane and carbon dioxide as its most significant products (Membere et al., 2012).

A source-separated organic waste from recyclable materials mainly consist of leftover foodstuffs, agricultural, human and animal excrements digested on-site in small anaerobic reactors may provide a vital solution to waste problems while reducing external energy requirements and greenhouse gas emissions at the same time (Chakraborty et al., 2019; Kader et al., 2015; Shrestha et al., 2017). The usual disposal of food waste in a landfill produces methane through an anaerobic digestion process from organic material and about half of the methane generated in the landfill escapes to the atmosphere which has 25 times stronger greenhouse effect than carbon dioxide (Chakraborty et al., 2019). In addition to methane, food waste in landfills can cause nutrient problems in leachate and odour and vermin problems, along with taking up unnecessary space in the landfills (Kader et al., 2015). Transporting and landfilling food waste also have a direct cost to businesses and many external costs to society with no economic benefits (Zupančič and Grilc, 2012).

Studies showed that roughly one-third of all food produced for human consumption each year goes to waste totalling 1.3 billion tones (Gustafsson et al., 2013). Applying anaerobic digestion to this amount of food waste has the potential to generate $367 \mathrm{~m}^{3}$ of biogas per dry tone at about $65 \%$ methane $(\mathrm{FAO}, 2011)$ with an energy content of $6.25 \mathrm{kWh} / \mathrm{m}^{3}$ of biogas yielding $894 \mathrm{TWh}$ annually. This represents almost $5 \%$ of the total global electrical energy utilization of 20,181 TWh in 2008 (Gustafsson et al., 2013).

In Ethiopia, at Wolaita Sodo University (hereafter, WSU), daily substantial quantities of food wastes are generated from food waste from vegetable residues, kitchen handling and cooking, preparation, food left overeating. There are different food waste categories based on daily food menu of the cafeteria and no appropriate 
methods of managing this food wastes. As it has been observed so far these valuable resources were disposed of in open spaces. The scenes around the university where the waste disposed of is unsightly and secondary pollution of groundwater and soil is inevitable and thus significantly degrading the environment. The disposal site is attracting garbage picking people and many other animals. In the eyes of the public, this practice somehow jeopardized the roles and purposes of the university. Moreover, a very large quantity of fuelwood is used for cooking purposes in the student cafeteria and resulting in exacerbating deforestation process in the area. Besides, a huge amount of soot and other dangerous volatile compounds released from burning fuelwood have detrimental health impacts to the cookers and hygiene or safety of the kitchen environments.

Currently, in Ethiopia, more than fifty Government-owned Universities which utilize their energy requirements from fuelwood and producing large quantities of food waste and disposing of it in traditional landfills. Therefore, in light of rapidly rising demands of energy, costs of energy and public concerns associated with waste disposal on the environment, conversion of food wastes to energy through anaerobic digestion becoming an economically viable and environmentally efficient practice not only producing biogas energy but also presents an opportunity to recover additional value from the waste material by producing nutrient-rich biofertilizer product that can be applied to agricultural land (Chakraborty et al., 2019). However, no studies have documented on the characterization and potential of various food wastes categories to biogas through anaerobic digestion. Therefore, the result of this study could have a significant contribution to the efforts to maximize renewable energy production from food wastes. With this consideration, food waste characterization and examination of each food waste category potential to biogas production will have paramount importance.

Therefore, the main aim of this study was to investigate the biogas production potential of food waste as a feedstock for anaerobic digestion processes at WSU, Ethiopia. More specifically to: (1) Characterize the various food waste categories collected from WSU students' cafeteria concerning bio digestibility (2) Evaluate the food waste categories as a potential feedstock for biogas production (3) Estimate the volume of potential biogas which could be produced from the food waste of WSU students' cafeteria.

\section{Materials and Methods}

\subsection{Description of the study area}

WSU was established in 2007 as a non-profit public higher education institution in Ethiopia, geographically located at $6^{\circ} 54^{\prime} \mathrm{N}$ latitude and $37^{\circ} 45^{\prime} \mathrm{E}$ longitude with an elevation of 1,600 in the urban setting of the small city of Woalaita Sodo, in Southern Ethiopia. This institution has also branch campuses officially accredited and/or recognized by the Ministry of Education, Ethiopia. WSU has a very large enrollment over 20,000 students for bachelor degrees, master degrees, and doctorate degrees in several areas of study.

\subsection{Food waste collection and Physico-chemical Analysis}

The food waste samples from WSU students' cafeteria were collected, separated and processed at teaching laboratories of Chemistry and Environmental Science departments in WSU. The food wastes in the cafeteria include various food items based on the variation of daily food menus of the university. Many different food items were available in the food menus such as "Injera", "Vegetables", "Rice", "Meat", "Shiro", "Lent", "Bread" and "Kinche". But, the samples were grouped into four categories based on the daily mill menu of the cafeteria. These were the mixture of "Injera" "Shiro" and "Vegetables" are grouped under the first category hereafter "ISV", the second category was the mixture of "Rice" and "Bread" hereafter "RB", the third category was the mixture of "Injera", "Meat" and "Lent" hereafter "IML", and the last category comprised the MA the food menu in the cafeteria. Except for the fourth category, the food waste under similar categories were the food wastes left over from similar mill time on the same day. Since the food waste as collected from temporary disposal outside the cafeteria (Figure 1) contained considerable impurities, such as wood, metal, cardboard, glass and plastics but screening operation is done strictly. 


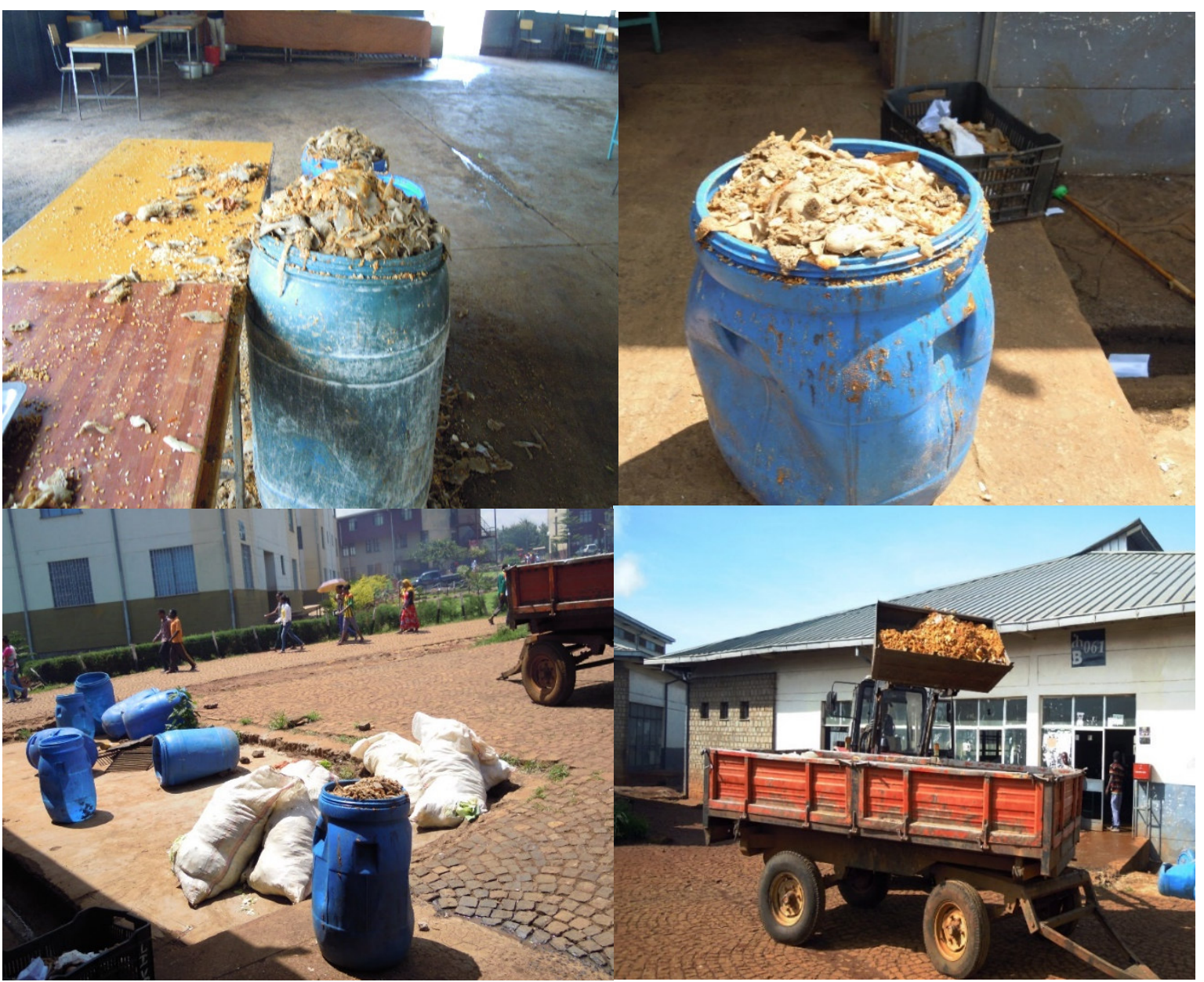

Figure 1 The food waste in WSU students' Cafeteria

To gain an understanding of the compositional variability of the food waste, ten samples of each of the four categories of the food wastes with one kilogram of each food waste category in a composite of five were collected from each of the food menus of the cafeteria. The raw waste was screened to remove the coarse contaminants and then finely ground by electric blender to maintain homogeneity and made small size for preparing it for anaerobic digestion. For each sampling, $100 \mathrm{~g}$ (wet weight) of the ground food waste samples were taken to food characterization and analyses at JIJE Labo-Glass laboratory, Addis Ababa, Ethiopia. All collected food waste samples were analyzed for percentage of total solids (\% TS) by AOAC Official Method 920.47, 940.09, 950.27; and percentage of volatile solids (VS) contents by (APHA $2540 \mathrm{E}$. Fixed and Ignited at $550^{\circ} \mathrm{C}$ ) and contents of percentage total nitrogen (\% TN) contents by AOAC Official Method 920.87 in JJJE Labo-Glass laboratory. The percentage of Total Solids (TS) was calculated as follows:

$\% \mathrm{TS}=\frac{(x-y)}{z-y} * 100$

Similarly, the percentage of Volatile Solids was calculated as follows:

$\% \mathrm{VS}=\frac{(x-t)}{x-y} * 100$

Where:

$\mathrm{x}=$ weight of dried residue + dish, $\mathrm{mg}$

$\mathrm{y}=$ weight of dish, $\mathrm{mg}$

$\mathrm{z}=$ weight of wet sample + dish, $\mathrm{mg}$

$\mathrm{t}=$ weight of residue + dish after ignition, $\mathrm{mg}$

And the percentage of total carbon was calculated as follows:

The carbon content of the feedstock is measured by considering the volatile solids content that was expressed as a percentage and the total carbon content was obtained from volatile solids data using an empirical equation as reported by (Badger et al., 1979; Haug, 1993):

Carbon $\%=\mathrm{VS}(\%) / 1.8$

\subsubsection{Anaerobic digestion tests}

The bio-digestibility of the collected food wastes were determined using batch anaerobic digestion tests. Digestion 
tests were performed on the food waste samples collected from the representative samplings of each food waste category. The composite samples were prepared by mixing similar food waste samples and then taking $100 \mathrm{~g}$ representative samples from the mixture of each food waste category. The food waste samples were digested in a batch digesters, at a mesophilic temperature $\left(35^{\circ} \mathrm{C}\right)$ which help to develop anaerobic bacteria (Barik and Murugan, 2012) using an electric water bath for 25 days in a pH of 7 (Budiyono et al., 2013) (Figure 2). Biogas from each digester was collected in a plastic bag (Figure 2). At the beginning of the digestion tests, in each digester, bacterial inocula were mixed with food waste.

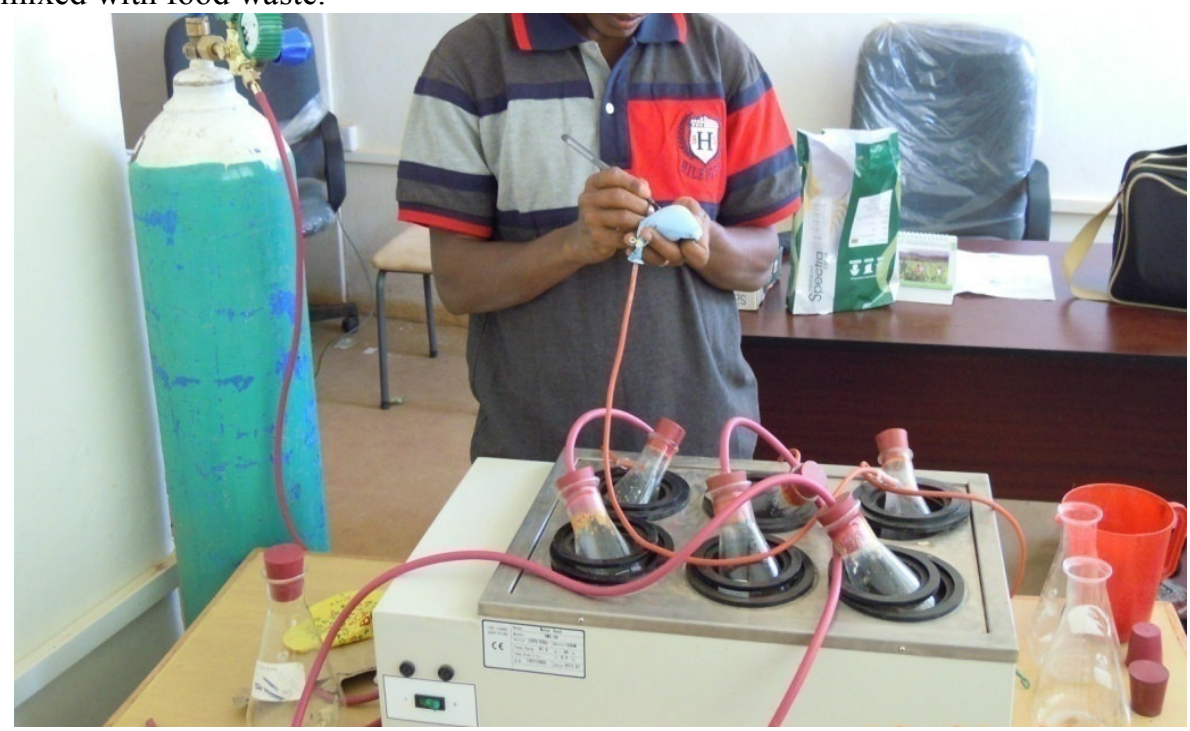

\subsubsection{Biogas measurements and gas quality}

Figure 2 Digesters inside the water bath during anaerobic batch digestion

Biogas samples generated from the anaerobic digestion of the sample food wastes with bacterial inoculum (methanogenic bacteria) at the laboratory were collected from the gas collection bubbles and analyzed for percentage of methane and carbon dioxide content were measured using "GA45 Infrared Gas analyzer" equipped with two (internal and external) filters at Environmental Protection Authority of Addis Ababa City administration (Figure 3). The volume of biogas produced from 100-gram food waste was measured by the water displacement method.

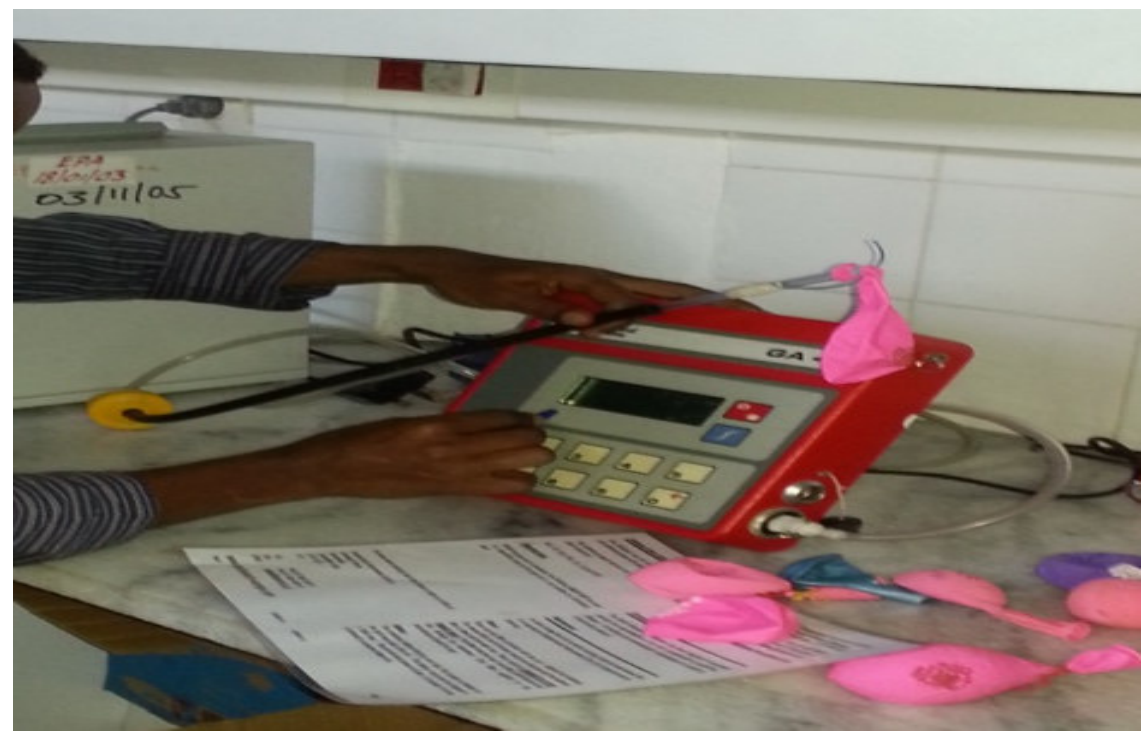

Figure 3 Measurement of biogas quality $\left(\mathrm{CH}_{4} \& \mathrm{CO}_{2}\right.$ proportion) by Geotechnical instruments GA45

\subsection{Data Analysis}

The Physicochemical parameters \% TN,\% VS, \% TS and \% TC of different category of the food wastes were analyzed and compared to each other, using line graphs and charts using IBM SPSS Statistics 21. Apart from this, the proportion of $\mathrm{CH}_{4}$ and $\mathrm{CO}_{2}$ obtained from each category of the food wastes were presented using tables and graphs. 


\section{Results and Discusions}

\subsection{Characteristics of food waste}

The highest percentages of total carbon content and total nitrogen contents, total solids and total volatile solids were scored from IML food waste category while the least percentages of total carbon content total nitrogen contents, total solids and total volatile solids were scored from IML food waste category (Table 1). The ratio of total volatile solids to total solids scored for ISV, RB, IML and MA were 95, 85, 95 and 95 respectively.

\begin{tabular}{|c|c|c|c|c|c|}
\hline Type Food waste & \%TN & \%TC & \% TVS & \% TS & TVS/TS (\%) \\
\hline ISV & 1.65 & 12.14 & 21.86 & 22.95 & 95 \\
\hline RB & 2.26 & 13.30 & 23.89 & 28.13 & 85 \\
\hline IML & 3.27 & 17.36 & 31.24 & 33.05 & 95 \\
\hline MA & 1.62 & 16.27 & 29.29 & 30.75 & 95 \\
\hline
\end{tabular}

Table 1 Elemental composition of each category of food waste mixtures

\subsubsection{Total Volatile Solids}

The percentages of total volatile solids scored from all food waste categories were in a range of 21.86 to 31.24 (Table 1). The highest and the least percentage of total volatile solids was scored in IML and ISV food waste categories respectively (Figure 4).

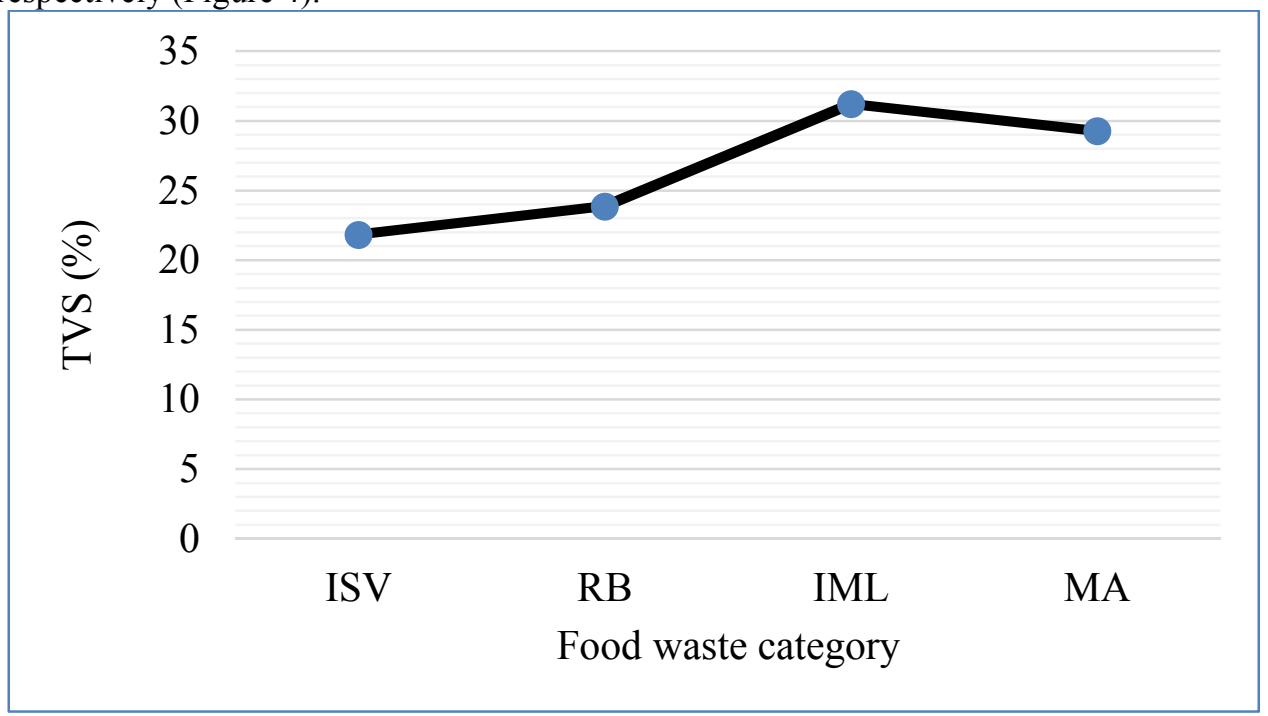

\subsubsection{Carbon to Nitrogen Ratio}

Figure 4 Percentage TVS in the food waste categories

The carbon to nitrogen ratio of ISV, RB, IML and MA food wastes were 7, 6, 5 and 10 respectively. Thus, the highest carbon to nitrogen ratio was scored from food waste category of MA indicating the high volume of biogas could be produced from MA food waste category (Saraswat et al., 2019). While the least carbon to nitrogen ratio was scored from IML (Table 2).

Table 2 carbon to nitrogen ratio of the four treatments

\begin{tabular}{|c|c|c|c|}
\hline Food waste & TC (\%) & TN (\%) & C/N ratio \\
\hline ISV & 12.14 & 1.65 & 7 \\
\hline RB & 13.3 & 2.26 & 6 \\
\hline IML & 17.36 & 3.27 & 5 \\
\hline MA & 16.27 & 1.62 & 10 \\
\hline
\end{tabular}

\subsection{Biogas Produced}

In the current study, the methane proportion of the biogas produced from the decomposition of food waste was ranged from $61 \%$ to $65 \%$ and the highest methane proportion was scored from RB food waste while the least methane proportion was scored from ISV food waste (Figure 5). The carbon dioxide proportion scored from the food waste categories ranged from $15.5 \%$ to $22 \%$ and the highest carbon dioxide proportion was scored from ISV food waste while the least carbon dioxide proportion was scored from IML food waste. Thus, a significantly higher quantity of methane was produced in comparison to carbon dioxide. The average volume of biogas generated from a 100 grams sample food waste of ISV, RB, IML and MA food waste categories was $67 \mathrm{ml}, 65 \mathrm{ml}$, $64 \mathrm{ml}$ and $68 \mathrm{ml}$ respectively. 


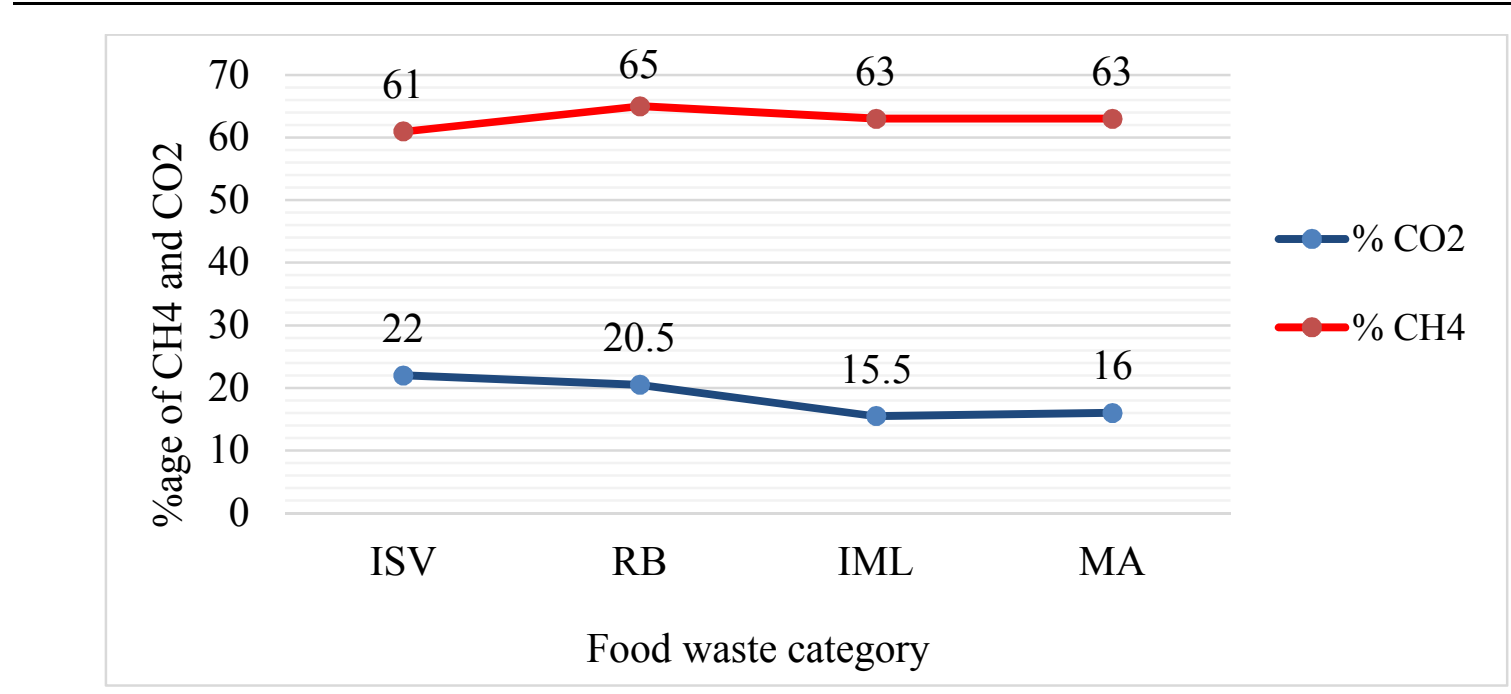

Figure 5 Proportion of $\mathrm{CH} 4$ and $\mathrm{CO}_{2}$ in the food waste categories

\subsection{Discussions}

Biogas production depends on various factors like temperature, $\mathrm{pH}$ value, $\mathrm{C}: \mathrm{N}$ ratio, hydraulic retention time (Saraswat et al., 2019). The total solid concentrations scored from all the food waste categories in this study ranged from 22.95 to $33.05 \%$ were deviated from a total solid concentration of 10\% (Paramaguru et al., 2017) and 7.5\% (Deepanraj et al., 2014) which were recommended as the suitable proportion of total solids for higher biogas production compared to less or higher percentage total solid concentrations. However, high volatile solids concentration relative to the total solids can speed up the anaerobic digestion and favour the food waste mixture as good feedstock for biogas production (Das, 2012). Thus, IML food waste category with the highest total volatile solids (31.24) could have the highest gas producing potential compared to the other food waste categories.

The $\mathrm{C}$ : $\mathrm{N}$ ratio obtained from the mixture of all food waste category was below 10 (Table 2) and this is in discrepancy with the optimum C: $\mathrm{N}$ ratio which is 20 to 30 recommended by previous studies (Achmad et al., 2011; Saraswat et al., 2019). This below optimum level of C: $\mathrm{N}$ ratio could occur due to the biomass used to have high nitrogen which is not easily digestible by microorganisms mostly methagenic bacteria in the reasonable time limiting the rate of biogas production (Prasad, 2012). It is generally found that during digestion, microorganisms utilize carbon 25 to 30 times faster than nitrogen (Dioha et al., 2013). Therefore, in such cases, the application of additional biomass that is rich in its carbon concentration to the digester during biogas production could have a significant contribution (Jigar et al., 2011). Thus, although all food waste category included in this study needs the addition of more carbon containing waste, IML food waste category with highest $\mathrm{C}$ : $\mathrm{N}$ ratio could have relatively better potential of biogas production than any other food waste category and the ISV have lowest potential of biogas production.

In this study, a significantly viable quantity of methane in the recommended combustible range of methane content which is $60 \%$ to $70 \%$ (Krich et al., 2005; Tarang et al., 2013) was produced. The highest volume of biogas was produced from MA food waste. Therefore, using the mixture of all the food waste should be used as feedstock for anaerobic digestion.

\section{Conclusions and Recommendations}

In this study, the evaluation of the food waste categories in terms of total solids, volatile solids, $\mathrm{C}: \mathrm{N}$ ratio, methane proportion and biogas production, in general, has shown insignificant variations except, slightly higher biogas production from the food waste category of RB compared to other food waste categories included in this studies. Despite its slight variations, the biogas produced from all the food waste categories was in its minimum combustible range of methane content $61-65 \%$. Since the variation between the biogas produced from all the food waste categories was insignificant and separating of food waste may take time and labour, producing the biogas from the mixed food waste should be preferred as feedstock for anaerobic digestion. Although, no significant difference in the produced biogas from the food waste categories, the convincing result was scored for biogas production using the food wastes as feedstock for biogas production. The $\mathrm{C}: \mathrm{N}$ ratio which is the other factor that can affect the rate of biogas production was scored as below the optimum level of biogas production from the food waste in need of an addition of other organic wastes which is rich in its carbon concentration inside the reactor. Using the mixture of all the food waste should be used as feedstock for anaerobic digestion. Therefore, the food left-over as a waste in the students' cafeteria of Universities should be used as an opportunistic energy source. Since the amount of biogas to be produced from the feedstock is based on the amount of food waste leftover which 
is mainly dependent on the number of students serving the cafeteria, the designing and construction of the biogas reactors for the food wastes should be in consideration of the increasing trend of total students in the university.

\section{References}

Abdulkareem, A., 2005. Refining biogas produced from biomass: An alternative to cooking gas. Leonardo journal of sciences 7, 1-8.

Achmad, K.T.B., Hidayati, Y.A., Fitriani, D., Imanudin, O., 2011. The effect of C/N ratios of a mixture of beef cattle feces and water hyacinth (Eichornia crassipes) on the quality of biogas and sludge. Lucrari stiintifice $55,117-120$.

Badger, D., Bogue, M., Stewart, D., 1979. Biogas production from crops and organic wastes. 1. Results of batch digestions. New Zealand Journal of Science 22, 11-20.

Barik, D., Murugan, S., 2012. Production and application of biogas as a gaseous fuel for internal combustion engines. International Journal of Engineering Research \& Technology (IJERT) 1, 2278-0181.

Bernstein, L., Bosch, P., Canziani, O., Chen, Z., Christ, R., Riahi, K. 2008. IPCC, 2007: climate change 2007: synthesis report (IPCC).

Budiyono, B., Syaichurrozi, I., Sumardiono, S., 2013. Biogas production from bioethanol waste: the effect of $\mathrm{pH}$ and urea addition to biogas production rate. Waste Technology 1, 1-5.

Chakraborty, D., Dahiya, S., Amulya, K., Srivastav, V., Mohan, S.V., 2019. Valorization of paper and pulp waste: Opportunities and prospects of biorefinery, In: Industrial and Municipal Sludge. Elsevier, pp. 623-656.

Das, D., 2012. Feasibility study of food waste to energy conversion through anaerobic digestion.

Deepanraj, B., Sivasubramanian, V., Jayaraj, S., 2014. Solid concentration influence on biogas yield from food waste in an anaerobic batch digester. In: 2014 International Conference and Utility Exhibition on Green Energy for Sustainable Development (ICUE), pp. 1-4.

Dinçer, İ., Abu-Rayash, A., 2019. Energy Sustainability. Academic Press.

Dioha, I., Ikeme, C., Nafi'u, T., Soba, N., Yusuf, M., 2013. Effect of carbon to nitrogen ratio on biogas production. International Research Journal of Natural Sciences 1, 1-10.

FAO, G., 2011. Global food losses and food waste-Extent, causes and prevention. SAVE FOOD: An initiative on Food Loss and Waste Reduction.

Gustafsson, J., Cederberg, C., Sonesson, U., Emanuelsson, A. 2013. The methodology of the FAO study: Global Food Losses and Food Waste-extent, causes and prevention”-FAO, 2011 (SIK Institutet för livsmedel och bioteknik).

Haug, R. 1993. The Practical Handbook of Compost Practical Handbook of Compost ractical Handbook of Compost Handbook of Compost andbook of Compost Engineering ngineering (Lewis Publishers, Florida, USA).

Jigar, E., Sulaiman, H., Asfaw, A., Bairu, A., 2011. Study on renewable biogas energy production from cladodes of Opuntia ficus indica. ISABB Journal of Food and Agricultural Sciences 1, 44-48.

Kader, F., Baky, A.H., Khan, M.N.H., Chowdhury, H.A., 2015. Production of biogas by anaerobic digestion of food waste and process simulation. American Journal of Mechanical Engineering 3, 79-83.

Kalmár, I., Nagy, V., 2007. Experiments on the maximum biogas production. Scientific Bulletin Series C: Fascicle Mechanics, Tribology, Machine Manufacturing Technology 21, 309.

Krich, K., Augenstein, A., Batmale, J., Benemann, J., Rutledge, B., Salour, D., 2005. Upgrading dairy biogas to biomethane and other fuels. Biomethane from dairy waste-A sourcebook for the production and use of renewable natural gas in California. California: Clear Concepts, 47-69.

Membere, E., Ugbebor, J., Akan, U., 2012. Biomechanization potential of organic fraction of municipal solid waste (OFMSW) from co-digestion of PIG and COW DUNG. International Journal of Environmental Sciences 2, 2387-2399.

Paramaguru, G., Kannan, M., Lawrence, P., Thamilselvan, D., 2017. Effect of total solids on biogas production through anaerobic digestion of food waste. Desalination and Water Treatment 63, 63-68.

Prasad, R.D., 2012. Empirical study on factors affecting biogas production. ISRN Renewable Energy 2012.

Saraswat, M., Garg, M., Bhardwaj, M., Mehrotra, M., Singhal, R., 2019. Impact of variables affecting biogas production from biomass. In: IOP Conference Series: Materials Science and Engineering, p. 012043.

Shrestha, S., Chaulagain, N.P., Shrestha, K.R., 2017. Biogas production for organic waste management: a case study of canteen's organic waste in Solid Waste Management Technical Support Center, Lalitpur, Nepal. Nepal Journal of Environmental Science 5, 41-47.

Tarang, B., Nikhil, T., Gaurav, C., 2013. Upgradation of biogas using combined method of alkaline water scrubbing and adsoption through carbon molecular sieve. International Journal of ChemTech Research 5, 886-890.

Zupančič, G.D., Grilc, V., 2012. Anaerobic treatment and biogas production from organic waste. Management of organic waste, $1-28$. 